\title{
Reports
}

\section{Systemic elevation of ACTH and hippocampal activity during classical conditioning of the rabbit nictitating membrane response}

\author{
RICHARD L. PORT, ANTHONY G. ROMANO, and MICHAEL M. PATTERSON \\ Ohio University, Athens, Ohio
}

\begin{abstract}
Hippocampal multiple-unit activity was recorded from rabbits injected with ACTH or with vehicle alone during classical conditioning of the nictitating membrane response. Elevated systemic levels of the hormone had no apparent effect on behavioral learning or on the hippocampal "model" of the conditioned response. Data from a control group, which received unpaired presentations of the CS and US, showed that the hippocampal response is learning-dependent. These results indicated that the behavioral effects of ACTH in intact animals is not, as previously conjectured, mediated by a disruption of hippocampal function.
\end{abstract}

Montgomery, Berkut, Grubb, and Westbrook (1971) first suggested that some of the deficits exhibited by braindamaged animals might be attributable to an increase in hormone levels as a consequence of the lesion. Noting that the delayed extinction of shuttlebox avoidance found in hippocampal lesioned animals (Isaacson, Douglas, \& Moore, 1961) could also be produced in intact animals by ACTH injection (Murphy \& Miller, 1955), Pagano and Lovely (1972) examined the effects of the hormone on the acquisition of avoidance responses. Their results indicated not only that ACTH injections accelerated acquisition, but that the performance of control animals correlated with the diurnal cycle of ACTH release. Thus, it was suggested that the facilitated acquisition found in hippocampal lesioned animals (Green, W. W. Beatty, \& Schwartzbaum, 1967) could also be mediated by increased levels of ACTH. In a later study, Lovely (1975) examined the effects of septal or hippocampal lesions on shuttlebox avoidance in hypophysectomized rats. In animals depleted of ACTH, septal damage facilitated acquisition; hippocampal damage had no significant effect. Thus, it appeared that the faster acquisition and slower extinction commonly associated with the "hippocampal syndrome" (Douglas, 1967) may not reflect a loss of hippocampal function per se, but could be mediated by hormonal actions elsewhere.

Our conceptualization of hippocampal involvement in learning is partly derived from the results of hippocam-

\footnotetext{
The research presented here was supported by National Institute of Neurological and Communicative Disorders and Stroke Grants NS10647 and NS14545, American Osteopathic Association Bureau of Research Grant 81-80-023, and the Ohio University College of Osteopathic Medicine. R. L. Port is currently in the Department of Psychology, University of Pittsburgh; A. G. Romano is in the Department of Psychology, Ohio University. Requests for reprints may be addressed to Michael M. Patterson, College of Osteopathic Medicine, Ohio University, Athens, OH 45701.
}

pal lesion studies. In brief, we have suggested that the hippocampus performs two separate functions related to plasticity (Port, Mikhail, \& Patterson, 1985). The first function concerns the initial representation of environmental stimuli within hippocampal activity. Vinogradova (1975) has shown that hippocampal neurons encode stimulus modality, onset, and termination. Hippocampal responses appear to be a relatively passive relay of entorhinal input and to decay rather quickly. However, the hippocampal "stimulus map" may be essential to learning in which evoked motor responses are absent. Hippocampal lesions have been found to abolish the retarding effect of nonreinforced CS preexposure typically found in latent inhibition (P. R. Solomon \& Moore, 1975) and to selectively impair an animal's ability to cease responding to a previously reinforced CS during discrimination reversal learning (Berger \& Orr, 1983). Damage to the fimbria was found to abolish sensory preconditioning (SPC, the association of two conditional stimuli) yet had no effect during CS-US training (Port \& Patterson, 1984).

The second hippocampal function related to plasticity is the generation of a "neural model" of learned behavioral responses. Berger and Thompson (1978) reported that hippocampal multiple-unit activity increased markedly during classical conditioning of the rabbit nictitating membrane (NM) response. The learning-dependent increase in pyramidal cell activity occurred early in training. Over conditioning trials, the hippocampal response moved forward in time, consistently preceding the behavioral conditioned response (CR) by roughly $40 \mathrm{msec}$. The amplitude timecourses of the neural and behavioral measures were highly correlated. Later studies have found similar hippocampal models of learned behavior during classical conditioning of the rabbit hindlimb (Thompson, Berger, Berry, Kettner, \& Weisz, 1980) and jaw-movement 
(Berry \& Oliver, 1982) responses and the cat NM response (Patterson, Berger, \& Thompson, 1979), and during instrumental conditioning of a leverpressing response in the rabbit (Holt \& Thompson, 1984). However, it has been difficult to ascribe a purposive role in associative learning to the hippocampal model, given the lack of deleterious effects of hippocampal lesions on simple learning.

In a study of the effect of the interstimulus interval (ISI) on the hippocampal model of the conditioned rabbit NM response, Hoehler and Thompson (1980) found that no behavioral learning or increase in hippocampal activity occurred when animals were trained with a 50-msec ISI. When a 150 - or 250 -msec ISI was employed, animals successfully acquired CRs and also displayed a marked increase in hippocampal activity which modeled the behavioral CR. Both the hippocampal and behavioral responses adjusted accordingly when the ISI was lengthened from 250 to $500 \mathrm{msec}$; however, the hippocampal response appeared to adjust more quickly. Thus it was postulated that the hippocampal model might serve as a "temporal map of the amplitude timecourse of the learned behavioral response to be made'" (Hoehler \& Thompson, 1980, p. 210).

The effects of hippocampectomy on NM conditioning at various ISIs indicate that the degree of hippocampal participation may be determined by the relative difficulty of the ISI. Smith, Coleman, and Gormezano (1969) reported that the ISI-conditioning function is concave (an inverted " $U$ "). Animals trained with backward, simultaneous, or very short (50-msec) ISIs showed no CR acquisition. Animals trained at 100-, 200-, 400-, and 800msec ISIs successfully acquired CRs. The rate of acquisition was slowest at $100 \mathrm{msec}$, most rapid at 200 and $400 \mathrm{msec}$, and moderate at $800 \mathrm{msec}$. Hippocampectomy was found to have no effect on conditioning when a moderate (300-msec) ISI was employed (Port, Mikhail, \& Patterson, 1985). However, when a short $(150-\mathrm{msec})$ or long (600-msec) ISI was employed, hippocampectomy accelerated the acquisistion of CRs. Thus, hippocampal participation appears to increase as the ISI departs from the "optimal" range.

Conceptually, the optimal range of ISIs may reflect the temporal predisposition of the neural substrate underlying the association. However, animals not only acquire CRs at short or long ISIs, but also time their responses dependent upon the ISI. Smith (1968) found that the peak latency of CRs on CS-alone (test) trials coincided with the usual time of US onset. The onset latency was proportional to ISI duration. Hence, it is possible that the basic associative response is modified to reflect the parameters of the stimulus configuration. The hippocampal model of the CR appears well suited for such a process. The selective facilitation of acquisition in short and long ISIs indicates that the modulatory process may delay the initial occurrence of CRs. At an optimal ISI, modulation may be unnecessary. Thus, hippocampectomy has no significant effect. If the hippocampus modifies the timing of learned behavior, hippocampal damage should, under certain conditions, alter the temporal characteristics of acquired responses. Hippocampal lesions have been reported to alter the onset latency (Port \& Patterson, 1984), topography (Orr \& Berger, 1985), and overall timing (Meck, Church, \& Olton, 1984) of learned behavior. The notion that the hippocampus modulates the timing of CRs dependent upon the stimulus configuration indicates a purposive yet nonessential role in associative learning for the hippocampal model.

In a recent study (Port, Mikhail, Kline, \& Patterson, 1985), we compared the effects of ACTH injection with those of bilateral hippocampal lesions during short (150$\mathrm{msec}$ ) delay conditioning of the rabbit NM response. Both manipulations facilitated the rate of acquisition and decreased the onset latency of CRs. There was no significant interaction between the treatments, and the effect of the hormone was dose dependent. However, in another experiment (Port \& Patterson, 1985), ACTH injections did not impede the performance of animals in SPC, a task presumed to require hippocampal participation. Additionally, ACTH injections did not accelerate acquisition during the CS-US training in which a moderate (300-msec) ISI was utilized. Thus, in classical conditioning, the hormone exerts an ISI-dependent effect much like that of hippocampectomy.

The incomplete replication of hippocampal lesion effects by ACTH treatment can be explained in several different ways. First, it remains possible that the two treatments have similar effects (facilitation of acquisition) that are mediated by independent means. Second, the deficit in SPC (and other paradigms devoid of evoked motor responses) could be due to a loss of hippocampal function, whereas the facilitation of acquisition could be mediated by the hormone. Third, both types of deficit could be attributed to a loss of hippocampal functions with ACTH selectively disrupting the neural model.

To examine the possibility that the facilitation of acquisition exhibited by hippocampal lesioned animals could be attributed to increased levels of ACTH, we pretreated hippocampectomized animals with dexamethasone, a potent synthetic glucocorticoid that decreases circulating levels of ACTH (P. A. Beatty, W. W. Beatty, Bowman, \& Gilchrist, 1970). Hypophysectomy was not utilized, due to the severe metabolic derangement and physical weakness which accompany the procedure. Dexamethasone treatment did not alter the facilitatory effect of hippocampal damage, nor did it affect the performance of control groups (Port, Romano, Mikhail, \& Patterson, 1984). To determine if ACTH could facilitate acquisition by acting on the hippocampal formation, microinjections of ACTH were delivered via cannulae into the dorsal hippocampus immediately prior to training. Pfaff, Silva, and Weiss (1971) have shown that the hormone has an excitatory effect on hippocampal pyramidal neurons, the population of cells which are the source of the model of the CR (Berger, Rinaldi, Weisz, \& Thompson, 1983). Intrahippocampal injection of ACTH facilitated the rate of acqui- 
sition and decreased the onset latency of CRs. Thus, it appeared feasible that ACTH could facilitate learning by altering hippocampal activity.

Many studies have found significant changes in associative learning following manipulation of hippocampal activity. Posttrial electrical stimulation of the dorsal hippocampus has been reported to retard (Salafia, Romano, Tynan, \& Host, 1977) or facilitate (Prokasy, Kesner, \& Calder, 1983) classical conditioning. Long-term potentiation of hippocampal synaptic transmission also accelerates acquisition (Berger, 1984), whereas cholinergic blocking via scopolamine treatment appears to retard conditioning by acting on the hippocampus (P. R. Solomon, S. D. Solomon, Vander Schaaf, \& Perry, 1983). Although the mechanisms by which changes in hippocampal activity influence behavior are not well understood, it is sufficient to note that altering hippocampal activity can have significant consequences on learned behavior.

The selective replication of deficits attributed to a loss of the hippocampal model (facilitation) suggests that the stimulatory effect of the hormone may influence the development of the hippocampal model while permitting the stimulus map to proceed intact. This would be consistent with the dynamics of each process. The stimulus map is a relatively passive relay of entorhinal signals; no transformation occurs (Vinogradova, 1975). The generation of the neural model appears to be an active process, occurring within the hippocampal formation (Berger, Laham, \& Thompson, 1980). Thus, the hippocampal model may be more susceptible to interference than the stimulus map. Another possibility is that different populations of hippocampal neurons may subserve the hippocampal model and the stimulus map. If the population that models the CR is sensitive to ACTH, this could account for the hormone's altering the development of the model without degrading the stimulus map. Although the pyramidal cells of the hippocampus are known to be heterogenous (Berger et al., 1983), those cells responsive to ACTH have yet to be isolated.

If ACTH influences the acquisition of CRs by blocking or impeding the development of the hippocampal model, it should be evident in the multiple-unit record of ACTH-injected animals. The present experiment examined hippocampal activity in ACTH-treated animals during classical conditioning. A moderate ISI was employed so that behavioral learning would be equivalent between groups and any differences in the correlation between neural and behavioral responses could not be due to different stages of learning.

\section{METHOD}

\section{Subjects}

The subjects were 18 experimentally naive male and female New Zealand albino rabbits. The animals weighed between 2.2 and $3.2 \mathrm{~kg}$ and were individually housed with ad-lib access to food and water. All procedures were carried out during the light portion of a $12-\mathrm{h}$ light, 12-h-dark cycle.

\section{Surgery}

Animals were anesthetized with fluothane (Halothane) and placed in a Kopf stereotaxic instrument. A midline incision was made on the subject's head and underlying fascia scraped away. The skull was aligned such that bregma was $1.5 \mathrm{~mm}$ higher than lambda. A hole was drilled through the skull at $4.5 \mathrm{~mm}$ caudal to and $5.5 \mathrm{~mm}$ lateral to bregma. Each subject was chronically implanted with an insulated stainless steel electrode with an exposed tip of $50 \mu$. Electrodes were localized in the CA1 pyramidal layer of the right dorsal hippocampus by monitoring physiological recordings during implantation. The electrode was cemented to the skull with dental acrylic and leads were attached to a permanently mounted headstage.

\section{Apparatus}

The NM preparation (Gormezano, 1966; Gormezano, Schneiderman, Deaux, \& Fuentes, 1962) and conditioning apparatus (Port \& Patterson, 1984) have been described in detail elsewhere. In brief, during training, subjects were restrained in Plexiglas boxes inside unlit soundproof chambers. NM movement was monitored with minitorque potentiometers. Stimulus delivery and data collection were controlled by an Apple II/FIRST computer system (Scandrett \& Gormezano, 1980). The CS was a $90-\mathrm{dB}$ tone; the US was a corneal air puff $(210 \mathrm{gm} / \mathrm{cm})$. White noise $(72 \mathrm{~dB})$ was present at all times during training.

Multiple-unit activity was amplified with battery-powered, solidstate FET amplifiers and recorded on magnetic tape. Tapes were bandpass filtered at $500 \mathrm{~Hz}$ to $5 \mathrm{kHz}$ through a Krohn-Hite electronic filter (Model 310A), and discharges of small groups of neurons were analyzed by a pulse-height discriminator (Mentor N-750 spike analyzer) set to pass larger units. Standard pulse output of the discriminator was analyzed off-line by the computer. The number of pulses per 5-msec time bins were counted for each trial and cumulated over sessions to create poststimulus histograms. Standard scores relative to activity in the pre-CS period were used in the statistical analyses.

\section{Procedure}

Animals were randomly assigned to an ACTH-injected group $(n=6)$, a sham-injected group $(n=6)$, or an unpaired control group $(\mathrm{n}=6)$. Initially, all subjects underwent a 30 -min adaptation session in the conditioning apparatus. Training began on the following day; each session included 64 reinforced trials with 16 nonreinforced (test) trials interspersed. The unpaired controls received 80 explicitly unpaired presentations of the CS and US. CS duration was $350 \mathrm{msec}$; US duration was $100 \mathrm{msec}$. The ISI was $250 \mathrm{msec}$ and the intertrial interval averaged $45 \mathrm{sec}$. Responses that exceeded $0.5 \mathrm{~mm}$ in amplitude and occurred during the ISI were scored by the computer as conditioned responses.

Animals in the ACTH group were given subcutaneous injections of ACTH (Sigma, $5 \mathrm{IU} / \mathrm{kg}$ body weight) suspended in approximately $1 \mathrm{ml}$ of corn oil. The previous experiment (Port, Mikhail, Kline, \& Patterson, 1985) had indicated that this dose effectively facilitated learning when a short ISI was utilized. The sham-injected and unpaired groups both received injections of the vehicle. Injections were given approximately 5 to $10 \mathrm{~min}$ prior to each session. All groups received three consecutive days of training. At the completion of training, each subject received a small electrolytic lesion made by passing current through the recording electrode. Animals were euthanized with sodium pentobarbital (Nembutal) and perfused through the carotid arteries with saline followed by $10 \%$ formalin. Coronal brain sections were stained with a Prussian blue reaction to verify recording sites.

\section{Histological}

Inspection of the coronal sections from each subject revealed that the tips of the recording electrodes were all in 


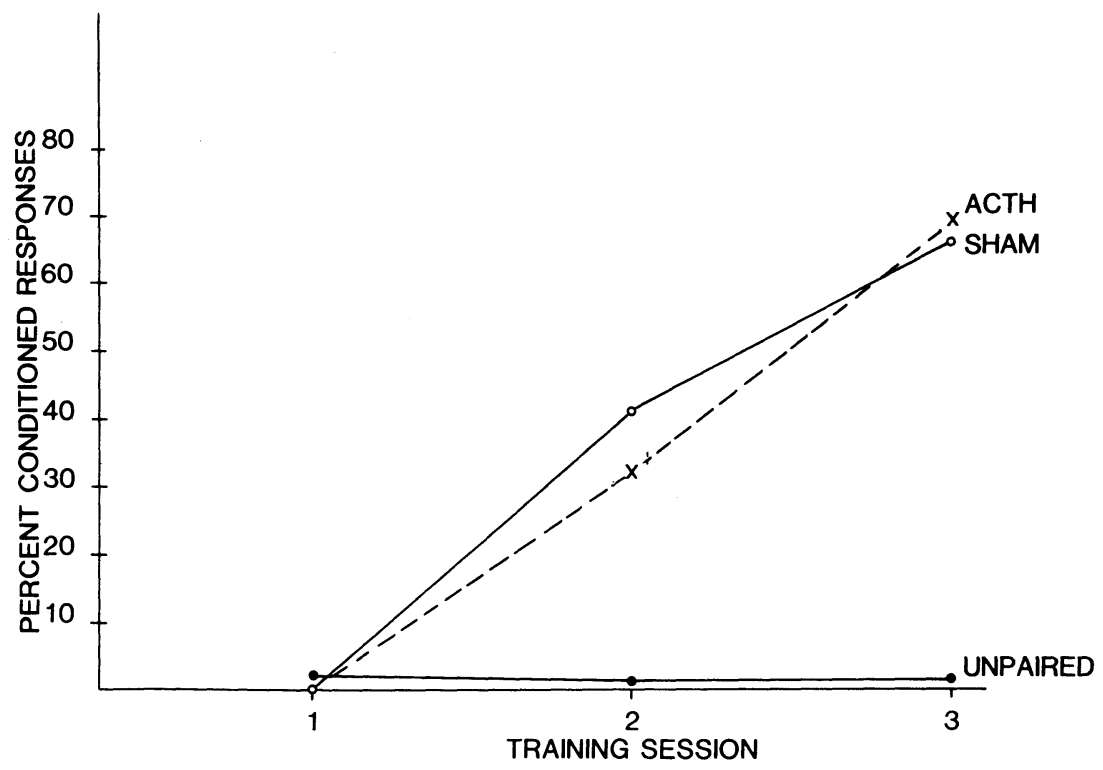

Figure 1. Acquisition rates plotted for all groups over training as percent conditioned responses.

or near the CA1 pyramidal cell layer of the dorsal hippocampus. (Reconstructions of all recording loci are available upon request; they are omitted here to save space.)

\section{Behavioral}

Rates of acquisition (see Figure 1) were analyzed as percent conditioned responses per session. A repeated measures analysis of variance (ANOVA) indicated significant effects of group $[\mathrm{F}(2,15)=7.49, \mathrm{p}<.01]$ and session $[F(2,30)=30.9, p<.01]$. The interaction $[\mathrm{F}(4,30)=8.05, \mathrm{p}<.01]$ also was significant. Appli- cation of Tukey's honestly significant difference (HSD) test $(p<.05)$ revealed that both paired groups increased response rates over training, whereas the unpaired group did not change. All other comparisons were nonsignificant $(\mathrm{p}>.05)$.

Mean onset latency of CRs was analyzed for the paired groups on Sessions 2 and 3 (see Figure 2). Data from the earlier session and from unpaired animals were excluded due to the small numbers of responses. A repeated measures ANOVA indicated a significant effect of session $[F(1,10)=19.1, p<.01]$. The group effect and inter-

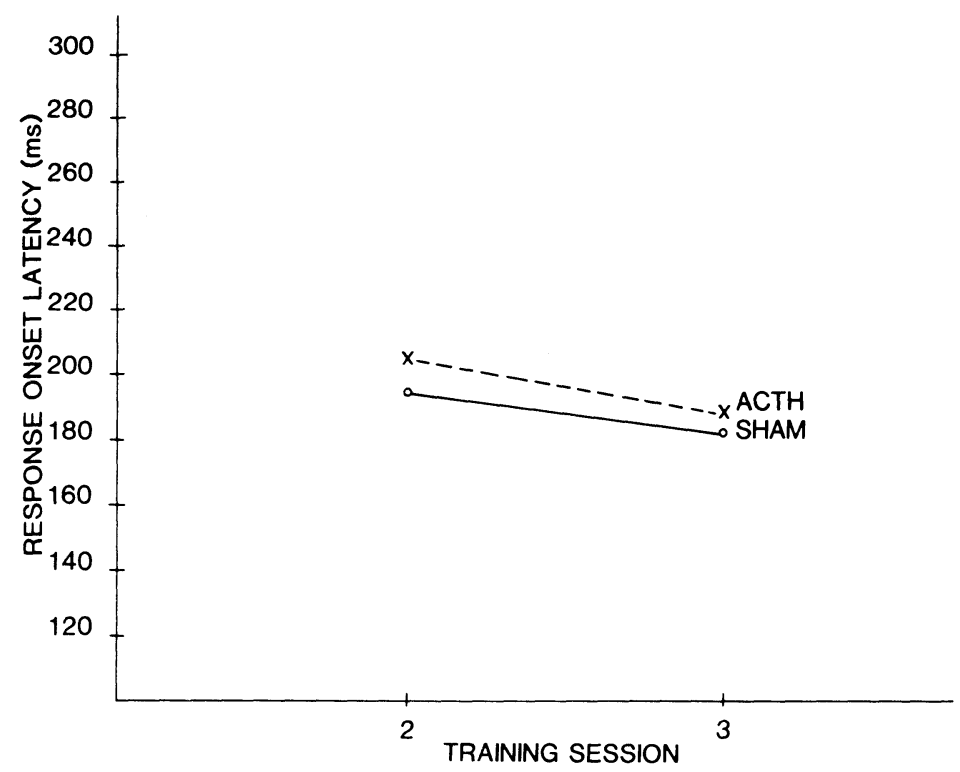

Figure 2. Mean onset latency of conditioned responses plotted over training for paired groups. Session 1 and the unpaired control groups were excluded due to the small numbers of responses. 
action were nonsignificant $(p>.05)$. The session effect appeared to reflect learning: onset latency decreased over training.

\section{Neural}

Neural data were analyzed using a "cross-correlation" procedure developed by Hoehler and Thompson (1980). In brief, a real-time correlation was computed for the amplitude measures of the neural and behavioral responses. The hippocampal response was then shifted $5 \mathrm{msec}$ later in time and a new coefficient was computed. Hoehler and Thompson suggested that the time shift is an accurate estimate of the latency difference between the hippocampal and behavioral responses.

Time-shifted correlations were computed for each subject and session (see Figure 3). The coefficients were converted to standard scores and were analyzed with a repeated measures ANOVA. The results indicated a significant effect of group $[F(2,15)=20.8, p<.01]$. The session effect and interaction were not significant. Application of Tukey's HSD test $(p<.05)$ revealed that both paired groups had correlation coefficients that were significantly greater than those of the unpaired group. Data from typical subjects in each of the three conditions are shown in Figure 4.

Restricted correlations, computed by matching the peaks of behavioral and neural responses, were also converted to standard scores and analyzed by ANOVA. The results indicated a significant effect of group $[\mathrm{F}(2,15)=17.7$, $\mathrm{p}<.01]$. The session effect and interaction were nonsignificant. Application of Tukey's HSD test $(p<.05)$ revealed that both paired groups had coefficients that were greater than those of the unpaired group.

\section{DISCUSSION}

The results of the present experiment indicate that systemic elevation of ACTH does not degrade the hippocampal model of the classically conditioned NM response.
Hippocampal activity in both ACTH-injected and shaminjected animals formed a temporal model of the behavioral CR. Consistent with earlier reports, multiple-unit activity did not increase markedly in unpaired animals, and the hippocampal response preceded the behavioral response by roughly $40 \mathrm{msec}$ in paired subjects. As expected, ACTH injections had no apparent effect on the rate of acquisition or timing of responses.

Because ACTH did not alter the correlation between the amplitude of hippocampal activity and the topography of the behavioral CR, our earlier speculation that the hormone facilitated acquisition by blocking the development of the hippocampal model was proven incorrect. However, it remains possible that the hippocampus is one of the sites at which ACTH acts to influence learning. It is also conceivable that the stimulatory effect of the hormone might enhance, rather than degrade, the hippocampal signal. It has not been determined whether enhancement of hippocampal transmission, as in long-term potentiation, has detectable effects on the multiple-unit record.

The notion that the facilitatory effects of ACTH treatment and hippocampectomy involve a common mechanism also remains tenuous. In classical conditioning, the onset latency of conditioned responses may be another index of learning (see Gormezano, Kehoe, \& Marshall, 1983). Onset latency tends to decrease over training, whereas the latency of response peak typically coincides with the usual time of US onset. Both hippocampectomy and ACTH injections produce a decrement in CR onset latency during short delay conditioning. The decrease is approximately $10 \mathrm{msec}$ and may be reflective of the advanced stage of learning. However, with longer ISIs, hippocampectomy can produce a robust decrement in $\mathrm{CR}$ onset latency that greatly exceeds the effect of training (Weisz, Solomon, \& Thompson, 1980; Beggs, Port, Romano, \& Patterson, 1985). We are presently evaluating the effect of ACTH injections on long delay conditioning to determine whether effects equivalent to hippocampectomy occur under these conditions.

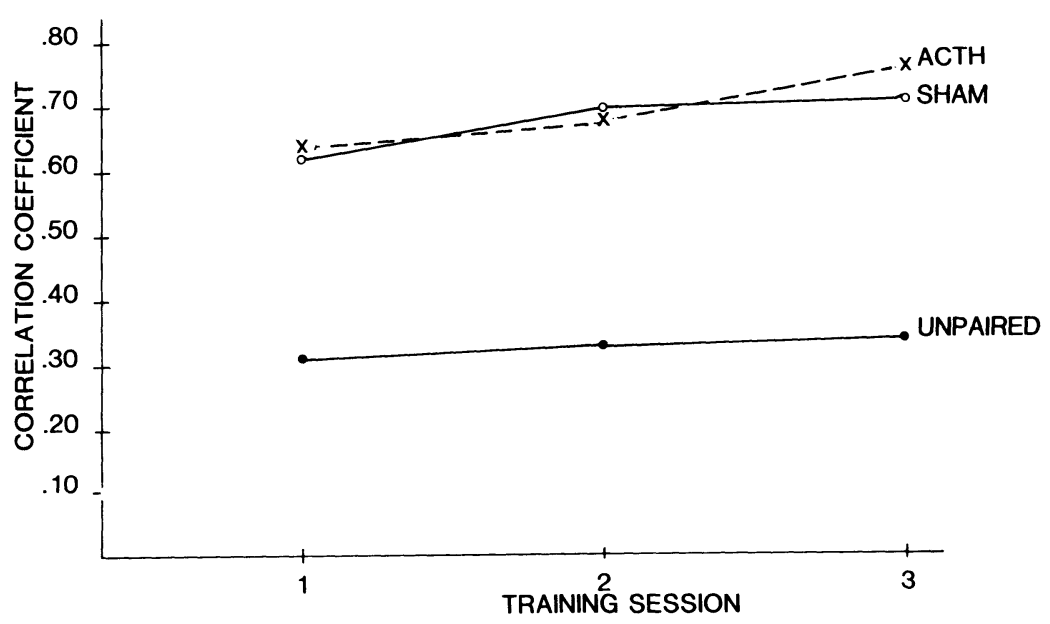

Figure 3. Temporally shifted correlation coefficients plotted over training for all groups. See text for details. 

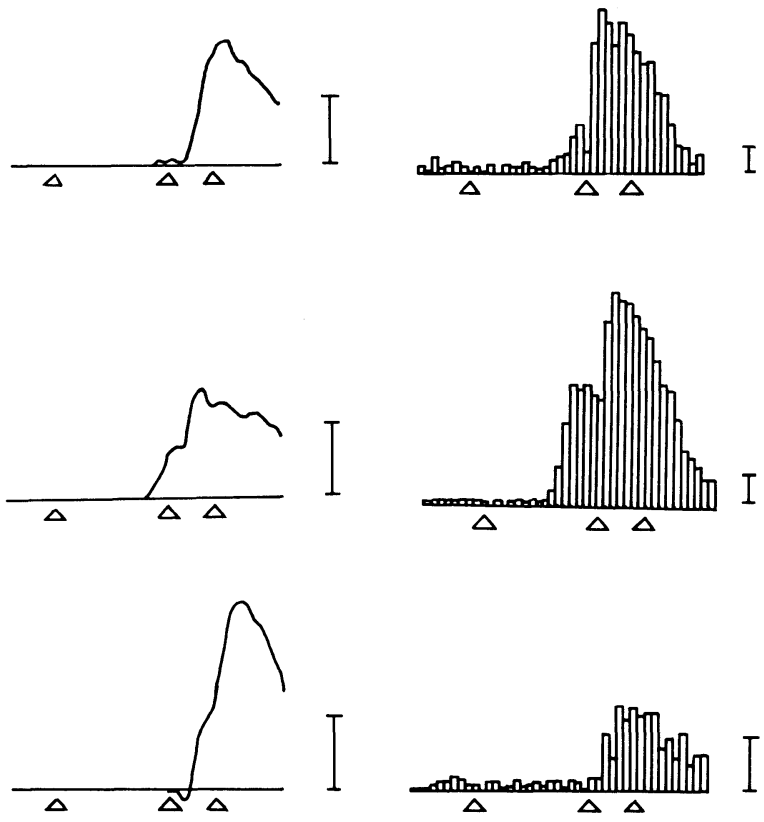

Figure 4. Representative behavioral (left) and neural (right) responses averaged over a training session for paired-vehicle (upper), paired-ACTH (middle), and unpaired control (lower) subjects. Bars equal $2 \mathrm{~mm}$ of NM extension or 1 standard score based on preCS (spontaneous) activity.

Yet another way in which ACTH could influence hippocampal neurons has recently been suggested. Sapolsky, Krey, and McEwen (1985) have found that prolonged exposure to glucocorticoids is lethal to some hippocampal neurons. Glucocorticoids appear to increase hippocampal vulnerability to metabolic insult (Sapolsky, 1985). Because potentiation develops within the hippocampus over the course of learning (Weisz, Clark, Yang, Thompson, \& Solomon, 1982), increased levels of ACTH (and associated glucocorticoids) could result in a significant loss of cells. Neuronal death may not be evident in the multiple-unit analysis because of the dependence on baseline measures. Although quite speculative, this hypothesis certainly warrants further consideration.

In summary, the present experiment showed that the effects of ACTH on classical conditioning are not mediated via disruption of the hippocampal model of the CR. Additional study is required to determine whether the effects of the two manipulations are identical and whether glucocorticoid toxicity could be involved in the behavioral effects of the hormone.

\section{REFERENCES}

Beatty, P. A., Beatty, W. W., Bowman, R. E., \& Gilchrist, J. C. (1970). The effects of ACTH, adrenalectomy and dexamethasone on the acquisition of an avoidance response in rats. Physiology \& Behavior, 5, 939-944.

Beggs, A. L., Port, R. L., Romano, A. G., \& Patterson, M. M. (1985). Hippocampectomy alters conditioned response onset latency in long delay conditioning. Society for Neuroscience Abstracts, 11, 527.
BERGER, T. W. (1984). Long-term potentiation of hippocampal synaptic transmission affects rate of behavior learning. Science, 224, 627-630.

Berger, T. W., Laham, R. I., \& Thompson, R. F. (1980). Hippocampal unit-behavioral correlations during classical conditioning. Brain Research, 193, 229-248.

BERGER, T. W., \& ORR, W. B. (1983). Hippocampectomy selectively disrupts discrimination reversal conditioning of the rabbit nictitating membrane response. Behavioral Brain Research, 8, 49-68.

Berger, T. W., Rinaldi, P. C., Weisz, D. J., \& Thompson, R. F. (1983). Single-unit analyses of different cell types during classical conditioning of the rabbit nictitating membrane response. Journal of Neurophysiology, 50, 1197-1219.

Berger, T. W., \& Thompson, R. F. (1978). Neuronal plasicity in the limbic system during classical conditioning of the rabbit nictitating membrane response. I. The hippocampus. Brain Research, 145, 323-346.

Berry, S. D., \& Oliver, C. G. (1982). Hippocampal activity during appetitive conditioning in rabbits. Society for Neuroscience Abstracts, 8, 315.

Douglas, R. J. (1967). The hippocampus and behavior. Psychological Bulletin, 67, 416-442.

Gormezano, I. (1966). Classical conditioning. In J. B. Sidowski (Ed.), Experimental methods and instrumentation in psychology (pp. 385420). New York: Appleton.

Gormezano, I., Kehoe, E. J., \& Marshall, B. S. (1983). Twenty years of classical conditioning with the rabbit. In J. M. Sprague and A. N. Epstein (Eds.), Progress in psychobiology and physiological psychology (Vol. 10). New York: Academic Press.

Gormezano, I., Schneiderman, N., Deaux, E. G., \& Fuentes, I. (1962). Nictitating membrane: Classical conditioning and extinction in the rabbit. Science, 138, 33-34.

Green, R. H., Beatty, W. W., \& Schwartzbaum, J. S. (1967). Comparative effects of septo-hippocampal and caudate lesions on avoidance behavior in rats. Journal of Comparative \& Physiological Psychology, 64, 444-552.

HoEHLER, F. K., \& ThOMPSON, R. F. (1980). Effect of the interstimulus (CS-UCS) interval on hippocampal unit activity during classical conditioning of the nictitating membrane response of the rabbit (Oryctolagus cuniculus). Journal of Comparative \& Physiological Psychology, 94, 201-215.

HolT, L., \& THOMPSON, R. F. (1984). Hippocampal correlates of instrumental behavior. Society for Neuroscience Abstracts, 10, 124.

IsaACSON, R. L., Douglas, R. J., \& MoORE, R. Y. (1961). The effect of radical hippocampal ablation on acquisition of avoidance response. Journal of Comparative \& Physiological Psychology, 54, 625-628.

Lovely, R. H. (1975). Hormonal dissociation of limbic lesion effects on shuttlebox avoidance in rats. Journal of Comparative \& Physiological Psychology, 89, 224-230.

Meck, W. H., Сhurch, R. M., \& Olton, D. S. (1984). Hippocampus, time and memory. Behavioral Neuroscience, 98, 3-22.

Montgomery, R. L., Berkut, M. K., Grubb, E. F., \& Westbrook, D. L. (1971). Hormonal influence on behavior in brain lesioned male rats. Physiology \& Behavior, 7, 107-111.

Murphy, J. V., \& Miller, R. E. (1955). The effect of adrenocorticotrophic hormone (ACTH) on avoidance conditioning in the rat. Journal of Comparative \& Physiological Psychology, 48, 47-49.

ORR, W. B., \& BERGER, T. W. (1985). Hippocampectomy disrupts the topography of conditioned nictitating membrane responses during reversal learning. Behavioral Neuroscience, 99, 35-45.

Pagano, R. R., \& Lovely, R. H. (1972). Diurnal cycle and ACTH facilitation of shuttlebox avoidance. Physiology \& Behavior, 8, 721-723.

Patterson, M. M., Berger, T. W., \& Thompson, R. F. (1979). Neuronal plasticity recorded from cat hippocampus during classical conditioning. Brain Research, 163, 339-343.

Pfaff, D. W., Silva, M. T., \& Weiss, J. M. (1971). Telemetered recordings of hormonal effects on hippocampal neurons. Science, 172, 394-395.

Port, R. L., Mikhail, A. A., Kline, M. A., \& Patterson, M. M. (1985). Neural and endocrine effects on classical conditioning: A com- 
parison of ACTH and hippocampectomy. Physiological Psychology, 13, 15-20.

Port, R. L., Mikhail, A. A., \& Patterson, M. M. (1985). Differential effects of hippocampectomy on classically conditioned rabbit nictitating membrane response related to interstimulus interval. Behavioral Neuroscience, 99, 200-208.

Port, R. L., \& Patterson, M. M. (1984). Fimbrial lesions and sensory preconditioning. Behavioral Neuroscience, 98, 584-589.

PoRT, R. L., \& PatTerson, M. M. (1985). Sensory preconditioning in the rabbit following ACTH injections. Physiology \& Behavior, 35, 443-445.

Port, R. L., Romano, A. G., Mikhail, A. A., \& Patterson, M. M. (1984). Neural and endocrine effects on learning: A contrast of hippocampal and ACTH influences. Society for Neuroscience Abstracts, 10, 126.

Prokasy, W. F., Kesner, R. P., \& Calder, L. D. (1983). Posttrial electrical stimulation of the dorsal hippocampus facilitates acquisition of the nictitating membrane response. Behavioral Neuroscience, 97, 890-896.

Salafia, W. R., Romano, A. G., Tynan, T., \& Host, K. C. (1977). Disruption of rabbit (Oryctolagus cuniculus) nictitating membrane conditioning by posttrial electrical stimulation of the hippocampus. Physiology \& Behavior, 18, 207-212.

SAPOLSKY, R. M. (1985). A mechanism for glucocorticoid toxicity in the hippocampus: Increased vulnerability to metabolic insult. Journal of Neuroscience, 5, 1228-1232.

SAPOLSKy, R. M., Krey, L. C., \& McEwen, B. S. (1985). Prolonged glucocorticoid exposure reduces hippocampal neuron number: Implications for aging. Journal of Neuroscience, 5, 1222-1227.

SCANDRETT, J., \& GoRmEZANO, I. (1980). Microprocessor control and A/D data acquisition in classical conditioning. Behavioral Research Methods \& Instrumentation, 12, 120-125.
SMITH, M. C. (1968). CS-US interval and US intensity in classical conditioning of the rabbit nictitating membrane response. Journal of Comparative \& Physiological Psychology, 66, 679-687.

Smith, M. C., Coleman, S. R., \& Gormezano, I. (1969). Classical conditioning of the rabbit's nictitating membrane response at backward, simultaneous, and forward CS-US intervals. Journal of Comparative \& Physiological Psychology, 69, 220-231.

SOLOMON, P. R., \& MoORE, J. W. (1975). Latent inhibition and stimulus generalization of the classically conditioned nictitating membrane response in rabbits following dorsal hippocampal ablation. Journal of Comparative \& Physiological Psychology, 89, 1192-1203.

Solomon, P. R., Solomon, S. D., Vander SchaAf, E., \& Perry, H. E. (1983). Altered activity in hippocampus is more detrimental to classical conditioning than removing the structure. Science, $\mathbf{2 2 0}$, 329-331.

Thompson, R. F., Berger; T. W., Berry, S. D., Kettner, R. E., \& WEISZ, D. J. (1980). Hippocampal substrate of classical conditioning. Physiological Psychology, 8, 262-279.

VINOGRADOVA, O. S. (1975). Functional organization of the limbic system in the process of registration of information: Facts and hypotheses. In R. L. Isaacson \& K. H. Pribram (Eds.), The hippocampus: Vol. 2. Neurophysiology and behavior (pp. 3-69). New York: Plenum Press. Weisz, D. J., Clark, G. A., Yang, B., Thompson, R. F., \& SoloMON, P. R. (1982). Activity of dentate gyrus during NM conditioning in rabbit. In C. D. Woody (Ed.), Conditioning: Representation of involved neural functions (pp. 131-145). New York: Plenum Press. Weisz, D. J., Solomon, P. R., \& Thompson, R. F. (1980). The hippocampus appears necessary for trace conditioning. Bulletin of the Psychonomic Society, 16, 164. (Abstract)

(Manuscript received June 30, 1985; revision accepted for publication September 12, 1985.) 